\title{
Complutum
}

ISSN: 1131-6993

http://dx.doi.org/10.5209/CMPL.64513

\section{Tésera uxamense con inscripción celtibérica}

Martín Almagro-Gorbea ${ }^{1}$; Xaverio Ballester ${ }^{2}$

Recibido: 15 de diciembre de 2018 / Aceptado 17 de mayo de 2019.

Se publica en esta nota una tésera de hospitalidad celtibérica que es propiedad desde hace años de un particular de la zona de Burgo de Osma, en Soria, quien por discreción ha preferido permanecer en el anonimato. Según la información obtenida, que consideramos fiable, la pieza procedería de esa zona de Burgo de Osma (Soria), la antigua Vxăma Argaela celtibérica, cuyo topónimo ha perdurado en el nombre de Osma (Tovar, 1989: 367 s.; TIR, 1993: 249 s.).

No se ha podido obtener información más concreta sobre el lugar y circunstancias del hallazgo de la pieza, de la que solo fue posible obtener las fotografías que aquí se publican, por lo que, como ocurre en estos casos, se debe mantener una cierta cautela sobre su autenticidad, aunque las características del documento se ajustan sin problemas a las que de las téseras zoomorfas celtibéricas, entre las que se conocen algunos ejemplares que pueden considerarse paralelos muy próximos desde el punto de vista tipológico.

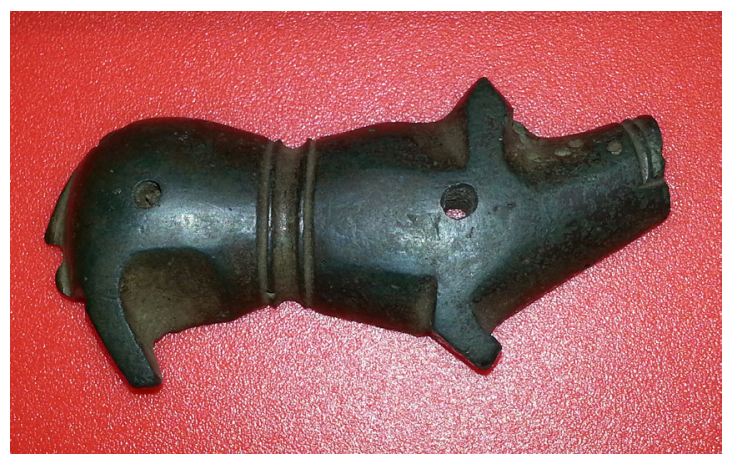

\section{Descripción}

Se trata de una tésera celtibérica de bronce, con una pátina verde rojiza, bien conservada y con la inscripción perfectamente legible (fig. 1,A-B). La pieza se ha obtenido a la cera perdida y presenta algunas pequeñas burbujas o fallos de fundición en la zona de la cabeza (fig. 2), que no le quitan calidad; tiene forma de un suido cortado longitudinalmente, ya que la parte conservada es una de las dos mitades simétricas que conforman este tipo de documentos, usados como testimonio jurídico para reconocer un pacto de hospitalidad.

La tésera parece representar a un suido, bien un cerdo o un jabalí. El animal, como se ha indicado, aparece cortado longitudinalmente y esta tésera representa el lado derecho, hacia el que mira el animal. En el centro de su cuerpo ofrece una moldura acanalada, que se ha supuesto que pudo tener la función de facilitar la colocación de una cinta para llevar la pieza colgada, aunque su aparición en diversos tipos de fíbulas inclina a con-

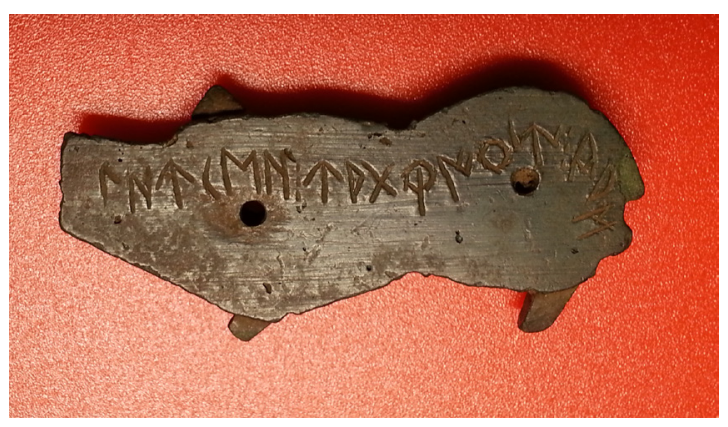

Figura 1. A-B, Tésera con forma de suido procedente de la zona de Vxama Argaela.

\footnotetext{
Real Academia de la Historia anticuario@rah.es

2 Universitat de Valéncia xaverio.ballester@uv.es
} 
siderarla un elemento decorativo. Además, a la altura del teórico eje longitudinal de la pieza, hacia la mitad del lomo y del vientre, la tésera ofrece dos perforaciones circulares que la atraviesan de parte a parte y que servirían para incrustar en ella sendos pivotes o vástagos que aseguraran la unión entre las dos mitades simétricas que conformaban el documento, para confirmar de ese modo que cada mitad, una con las dos perforaciones y otra probablemente con los pivotes correspondientes, formaban parte del mismo documento de hospitalidad.

La figura de esta tésera ofrece una estilización del suido de gran efecto estético, pues su estilizado diseño ha sabido esquematizar al animal con evidente maestría, hasta sugerir unas formas casi cubistas. Destacan los cuartos traseros de formas redondeadas, pero con la pata delantera angulada y la posterior resaltada por un amplio rebaje en forma de casquete esférico, la cabeza con un gran hocico remarcado en su extremo por una doble incisión y ligeramente alzado hacia arriba, la oreja en forma de un pequeño apéndice triangular apuntado y hacia arriba, que contrasta con las patas cortas, casi convertidas en apéndices de forma rectangular. Sobre el aspecto que ofrece este tipo tan concreto de tésera zoomorfa se ha llegado a señalar que "estas características morfológicas, aunque exageradas, corresponden a las del cerdo de raza céltica de orejas pequeñas y hacia arriba y cuartos traseros muy destacados. Dicha raza, llamada «large Withe [Large White] o York [Yorkshire]», siempre ha sido muy abundante en la zona norte de la península" (Faria 1998).

La tésera tiene su cara posterior lisa, para mejor adaptarse a la otra parte y para facilitar la inscripción (fig. 1,B y 6,A-B). En su centro, ofrece una leyenda escrita con claridad en escritura y lengua celtibéricas, formada por 16 signos profundamente incisos que quedan separados en tres partes por dos interpunciones de 3 puntos (vide infra):

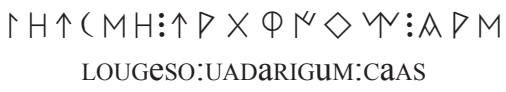

Dimensiones: Longitud máxima: $6,5 \mathrm{~cm}$. Altura máxima: $2,7 \mathrm{~cm}$. $(3,5 \mathrm{~cm}$ con patas y orejas). Grosor: $0,7 \mathrm{~cm}$.

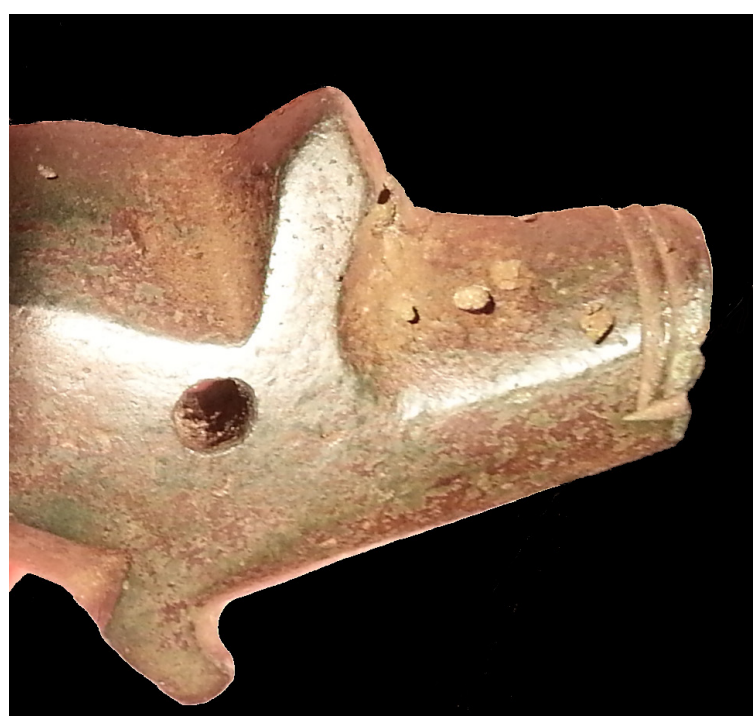

Figura 2. Detalle de la cabeza del suido con burbujas de fundición.

\section{Estudio tipológico}

Las téseras celtibéricas son documentos de gran interés y bien valorados. Entre ellas, algunas ofrecen forma de jabalí, como este ejemplar, aunque nuestra pieza destaca por la figura del animal representado, un suido muy estili- zado, con formas casi cubistas, que le dan gran personalidad. Se conocen otros dos ejemplares con esta misma forma (vide infra). Uno procede del yacimiento celtibérico de La Custodia, en Navarra (Labeaga y Untermann, 1994, 46; Untermann, 1997, 697, к.18.1; Simón, 2013, 328 s., 441, $\mathrm{n}^{\mathrm{o}} \mathrm{T} 12$ ), y otro es de proceden- 
cia desconocida y, al parecer, se conserva en la colección Daehnhardt, de Lisboa (Faria, 1998; Simón, 2013, 469 s., $\mathrm{n}^{\mathrm{o}}$ TS11).

Las téseras celtibéricas en forma de suido, probablemente un jabalí, son relativamente numerosas, pues, en la actualidad, se conocen 9 piezas, aproximadamente un 13\% del total de las conocidas (Almagro-Gorbea y Ballester, 2017: fig. 5). De ellas, 5 tienen procedencia segura: La Custodia en Navarra (Labeaga, 1987; Untermann, 1997: 697 s., $\mathrm{n}^{\circ}$ K.18.1; Simón, 2013: ${ }^{\circ}$ T12), Monte Bernorio (Torres y Ballester, 2014) y Herrera de Pisuerga (García Bellido, 1996; Castellano y Gimeno, 1999), en Palencia, y dos de Vxama Argcela, Osma, Soria, la aquí publicada y otra dada a conocer anteriormente (Untermann, 1997, 708 s., $n^{\circ}$ K.23.2; Simón, 2013, nº T11); otras 2 se suponen halladas respectivamente
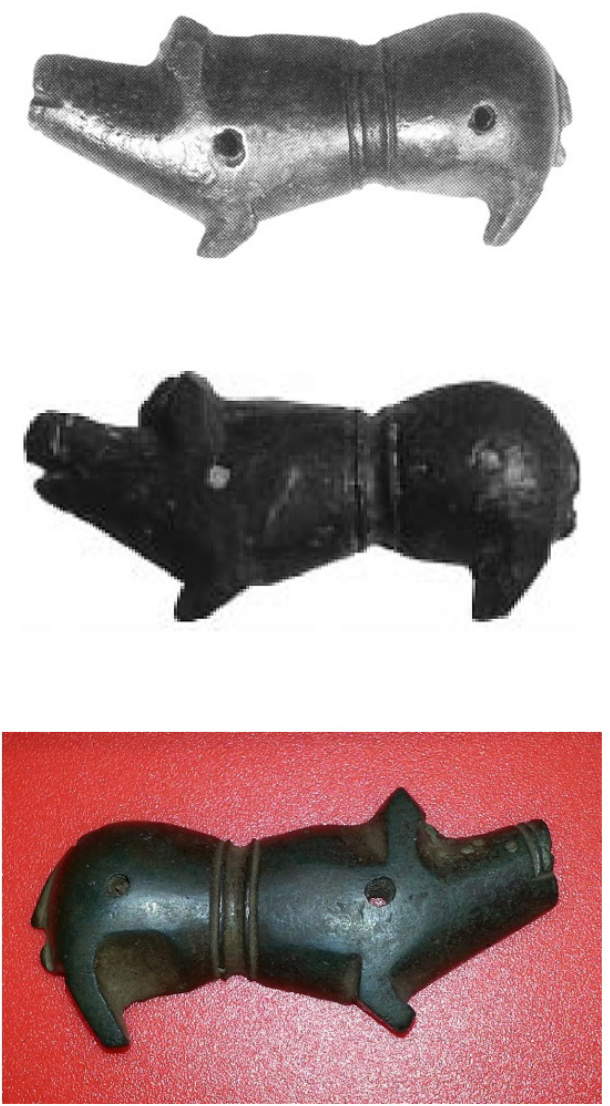

en las provincias de Cuenca (Tovar, 1983; Untermann, 1997, 546 s., ${ }^{\circ}$ к.0.6; Almagro-Gorbea et al., 2004: 308 s., no 606) y de Ávila (Turiel, 2000, 305 s.; Almagro-Gorbea y Turiel, 2003, 214 s.; Almagro-Gorbea et al., 2004: 299 s., n ${ }^{0} 593$ ) y 2 más carecen de procedencia (Faria, 1998, $n^{\circ} 1$ y 2). De estas téseras de suido, cinco tienen forma de bulto redondo cortado longitudinalmente: la aquí publicada de Vxama Argaela-2, La Custodia, una de la colección Daenhnhardt (Faria, 1998, $n^{\circ}$ 1), otra de Cuenca y otra de Ávila, además de otra de la colección Daenhnhardt (Faria 1998, $\mathrm{n}^{\circ}$ 2), que se ha llegado a considerar un oso por su morro recto y porque las patas parecen tener dedos hacia adelante. Las tres téseras restantes ofrecen forma de chapa plana: Vxama Argcela-1, Herrera del Pisuerga y Monte Bernorio.

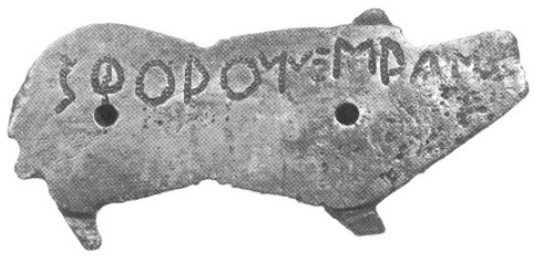

A

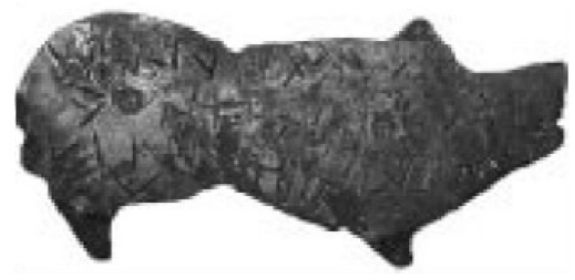

B

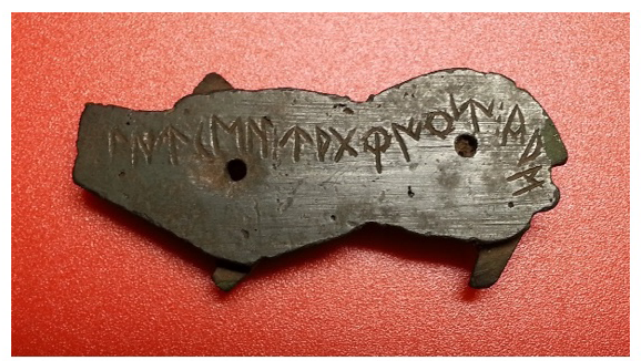

C

Figura 3. A, Anverso y reverso de la tésera de La Custodia (Untermann, 1977), de la Colección Daehnhardt (Faria, 1989) y de Vxama Argaela (C). 
Entre estas nueve téseras en forma de suido destacan tres ejemplares que ofrecen el mismo tipo exacto que esta tésera de Vxama Argcela, hasta el punto de que a primera vista parecen haber salido las tres del mismo molde y, en cualquier caso, deben considerarse producidas en el mismo taller y presumiblemente por el mismo artesano (fig. 3,A-C). Una, procedente del yacimiento beron de La Custodia, Viana, en Navarra, corresponde a la mitad izquierda del animal y mide $6,4 \mathrm{~cm}$ de largo por $2,8 \mathrm{~cm}$ de alto, $1 \mathrm{~cm}$ de grueso y pesa $47 \mathrm{gr}$ (Labeaga y Untermann, 1994, 46; Untermann, 1997, 697, K.18.1; Simón, 2013, 328 s., 441, no T12). Otra, por desgracia de procedencia desconocida, se conserva en la colección Rainhart Daehnhardt, de Lisboa y corresponde también a la mitad izquierda del animal y mide igualmente $6,4 \mathrm{~cm}$ de largo por 2,8 cm de alto (Faria, 1998; Simón, 2013, 469 s., $n^{\circ}$ TS11). La tercera es la aquí publicada, de $6,5 \mathrm{~cm}$ de longitud, $2,7 \mathrm{~cm}$ de altura y $0,7 \mathrm{~cm}$ de grosor.

Estas tres téseras ofrecen la característica de tener en el centro del cuerpo del suido una moldura formada por una triple escocia, más ancha la central, que queda resaltada por dos toros bastante agudos. Este detalle relaciona estas téseras con otras piezas que ofrecen ese tipo tan característico de moldura, lo que permite precisar su zona de origen y aproximarse a su cronología, aunque la mayoría de estos paralelos ofrecen una fecha bastante imprecisa y en muchas ocasiones se desconoce incluso su procedencia.

Este tipo de moldura, simple o múltiple, es propia de algunos tipos de fíbulas zoomorfas de la Meseta Norte (Schüle, 1969, mapa 47), especialmente con forma de jabalí o de "verraco", de tipo evolucionado pues algunos ejemplares ofrecen el pie unido al puente, característica de las fíbulas de transición de La Tène II hacia la La Tène III (fig. 4A).

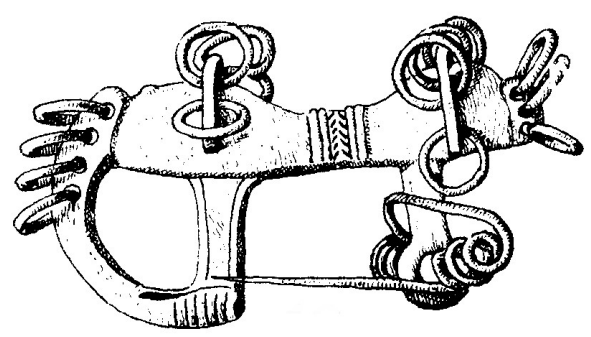

Figura 4A. Fíbula de verraco de la tumba 60 de la necrópolis de Miraveche, Burgos.
Este tipo de fíbula con moldura está representado en La Custodia, Viana, Navarra, por 4 ejemplares, que suponen un $8 \%$ de las fíbulas halladas (Labeaga, 1989: 648 s., fig. 2,8-9 y 11; id., 2006, fig. 6, $\mathrm{n}^{\circ} 44,45,47,48$ ), yacimiento que se ha identificado con la Vareia prerromana (TIR, 1993: 236), importante población de los bérones (Tovar, 1989: 77 s.), probablemente destruida durante las guerras sertorianas, pues Sertorio tomó Vareia en el 76 a.C. (Liv. fragm. 91), aunque no se debe descartar su destrucción en las guerras civiles entre César y los pompeyanos. También se conoce en Álava un ejemplar en Henayo (Lenetz de Wilde, 1991: lám. 1,3) y dos de Iruña (Caprile, 1986: p. 233, lám. 11,11 y 12,1) y otro en la "tumba 60" de Miraveche, al norte de Burgos (Schüle, 1969, lám. 147, no 18). Este tipo de fíbula está bien representado en la zona palentina, pues se conocen diversos ejemplares en la necrópolis de Paredes de Nava, Palencia (Schüle, 1969, lám. 164, no 10 y 11), la antigua Intercatia vaccea (Tovar, 1989: 332; $T I R, 1993,132 \mathrm{~s}$.), donde las fíbulas de verraco son 6 de las 23 publicadas, $c a$. 25\%, 4 de ellas con esta moldura característica, lo que supone ca. 17\% (Moure y Ortega, 1981, fig. 1, $\mathrm{n}^{\circ}$ $5,6,8$ y 9), proporción que resulta significativa. Además, a ellas pudieran sumarse otras sin procedencia del Museo Arqueológico Nacional que se consideran de las necrópolis palentinas (Álvarez-Ossorio, 1941: lám. 64; Lenetz de Wilde, 1991: lám. 234, no 960) y del Instituto Valencia de Don Juan (Schüle, 1969, lám. 172, $\mathrm{n}^{\circ} 26$ ). Por el contrario, este tipo resulta minoritario en Lancia (Cerdeño y Cabanes, 1994: fig. 5,2), Numancia (Id., lám. 170, nº 14) y en Valdenovillos, en Alcolea de las Peñas, Guadalajara (Schüle, 1969, lám. 24, no 7; Argente, 1989: tipo B.1.1, fig. 70, $\mathrm{n}^{\circ}$ 650), lo que confirma su procedencia de la franja norte de la Meseta.

Molduras con escocias son también características de fíbulas fundidas de La Tène II evolucionada (Cabré y Moran, 1979: fig. 13,7-11; id., 1982: 22, fig. 28,3-6; Lenerz-de Wilde, 1991: no 173, 176-179, 181, de Las Cogotas, Ávila; 195, de Cova Freda, Barcelona; 274, de Carboneras, Cuenca; 363-365, de Aguilar de Anguita, Guadalajara; 390, de La Olmeda; 417-418 de Torresabiñán, Guadalajara; 711-740, de Numancia; 880-884 de $A r$ cobriga, Zaragoza; 954, 956, sin procedencia, etc.), fechadas en el siglo II e inicios del I a.C. y cuya fabricación a la cera perdida las aproxima a las citadas téseras de verraco con moldura. Entre estas fíbulas, destacan las denomina- 
das "de fundición pesada" (Lenerz-de Wilde, 1991: 210, fig. 11), entre las que se incluye la argéntea del Tesoro de Torre de Juan Abad, Ciudad Real (Raddatz, 1969, 265, lám. 79, ${ }^{\circ}$ 5), bien datada c. 100 a.C. (Chaves, 1996, 138 s.) y otras fíbulas lupiformes (Lorrio, 2007, fig. 1 y 2), cuya fecha cabe situar igualmente en el siglo II avanzado o incluso a inicios del I a.C., como la de Arcobriga, datada, sin precisión, "en un momento avanzado del siglo III o ya del II a.C" (Lorrio y Sánchez del Prado, 2009, 387, fig. 172, $\mathrm{n}^{\circ} 16$ ).

También algunas fíbulas de "caballito" ofrecen esta característica moldura, en ocasiones en el caballo, como un ejemplar inédito del mercado de antigüedades probablemente procedente de la zona de Miraveche o de Villanueva de Teba, en la Bureba (fig. 4B). Otras veces aparece en el jabalí asociado, como en la fíbula de caballito de Arce Mirapérez, la antigua Deobri$g a$, en Miranda de Ebro, Burgos, que representa el $25 \%$ de las 4 publicadas (Abásolo y Ruiz, 1978, 265, lám. 1,1; Lenetz de Wilde, 1991: lám. 81, no 201d; Almagro-Gorbea y Torres, 1999, 127, lám. 8,1). También parece ofrecer esta moldura, aunque menos marcada, el jabalí de una fíbula de jinete de Numancia (Jimeno et al. 2004: 82, $\mathrm{n}^{\circ}$ T32,9 y 132, $\mathrm{n}^{\circ}$ T108,2; Almagro-Gorbea y Torres, 1999, 122, lám. 11,5) y el de otra fíbula de caballito de la provincia de $\mathrm{Pa}$ lencia (Schüle 1969, lám. 172,5; Lenetz de Wilde, 1991: 340, n 1040; Almagro-Gorbea y Torres, 1999, 141).

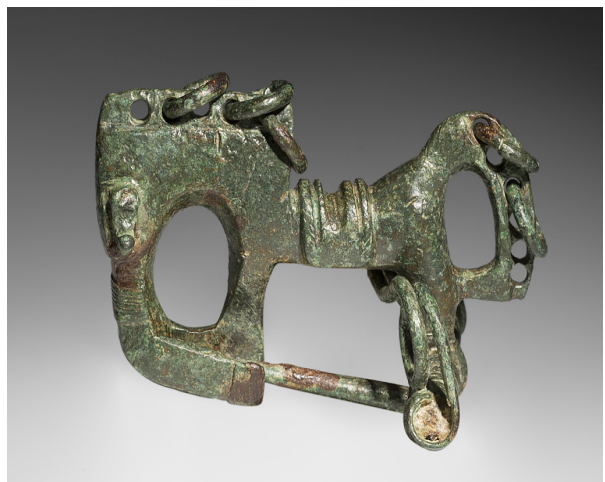

Figura 4B, Fíbula del mercado de antigüedades en forma de caballito.

Dentro de estos paralelos estilísticos, es interesante que esta moldura aparece representada en el suido grabado en dos broches de cinturón bastante excepcionales, uno de la necrópolis de Miraveche, Burgos, que se supone de la "tumba 60" (Schüle, 1969, lám. 147, nº
15; Lenetz de Wilde, 1991: no 207, lám. 85c) y otro de la necrópolis de Busto de Bureba (Rovira y Sanz, 1982: 45; A. Lorrio, comunicación personal), ambos, sin duda del mismo taller y, muy probablemente del mismo artesano (fig. 4C-D). La decoración zoomorfa de estos broches con un jabalí también recuerda la de otro broche de Toledo con dos jabalíes nielados muy pequeños (Cabré, 1937: lám. 24; Cerdeño y Cabanes, 1994: 108, fig. 7,1), otro de Gormaz con caballos (Lenetz de Wilde, 1991: lám. $181, n^{\circ} 633$ y lám. 182, no 645) y otro de La Osera con un enfrentamiento entre dos guerreros (id., lám. 9A, nº 51), aunque el estilo de estos broches es diferente. Los broches con suido de Miraveche y Busto de Bureba ofrecen una banda de ondas en su extremo distal que los relaciona con otro de Miraveche (Labeaga, 1992, fig. 3, $\mathrm{n}^{\mathrm{o}} 1$ ), que ofrece una especie de trisquel de cuatro brazos con extremos ondulados como evolución de una esvástica como la de otro cinturón de Paredes de Nava, Palencia (id. fig. $3, \mathrm{n}^{\mathrm{o}} 3$ ) y la citada pieza de Miraveche (Labeaga, 1992, fig. 3, $\mathrm{n}^{\circ} 1$ 1). Además, ambos tienen el contorno bordeado por una moldura formada por SS troqueladas entre líneas paralelas (ibidem), como otros broches más sencillos de La Custodia (Labeaga, 1992, fig. 3, $\mathrm{n}^{\circ}$ 6-7, fig. $6, \mathrm{n}^{\circ} 1$, fig. $7, \mathrm{n}^{\circ} 1$ y 2 , etc.). En conclusión, las características de los broches con suido de Miraveche y Busto de Bureba indican que son originarios de la Bureba, zona próxima a la frontera entre autrígones y bérones, en cuyo territorio también aparecen fíbulas con la moldura central indicada, aunque no se pueda descartar la zona septentrional de Palencia.

En consecuencia, los paralelos formales de esta tésera de hospitalidad en forma de suido indican que debe ser originaria de las áreas septentrionales de la Meseta Norte, probablemente del territorio autrigon de la actual $\mathrm{Bu}-$ reba, sin que se pueda excluir su fabricación en territorios vecinos de los bérones o de los vacceos septentrionales. Su origen muy probable en la Bureba y su hallazgo en tierras arévacas de Vxama Argcela documenta una vez más el carácter móvil de las téseras, hecho que se corresponde con su función. De este modo, se añade al creciente número de téseras encontradas fuera de su lugar de producción, en algunos casos a gran distancia (García Bellido, 1996: fig. 17; Almagro-Gorbea y Lorrio, 1986: mapa 6; Untermann, 1997: 437, mapa 5; Simón, 2008: mapa 3; id., 2013, mapa 3; Almagro-Gorbea y Ballester, 2017, fig. 6). 

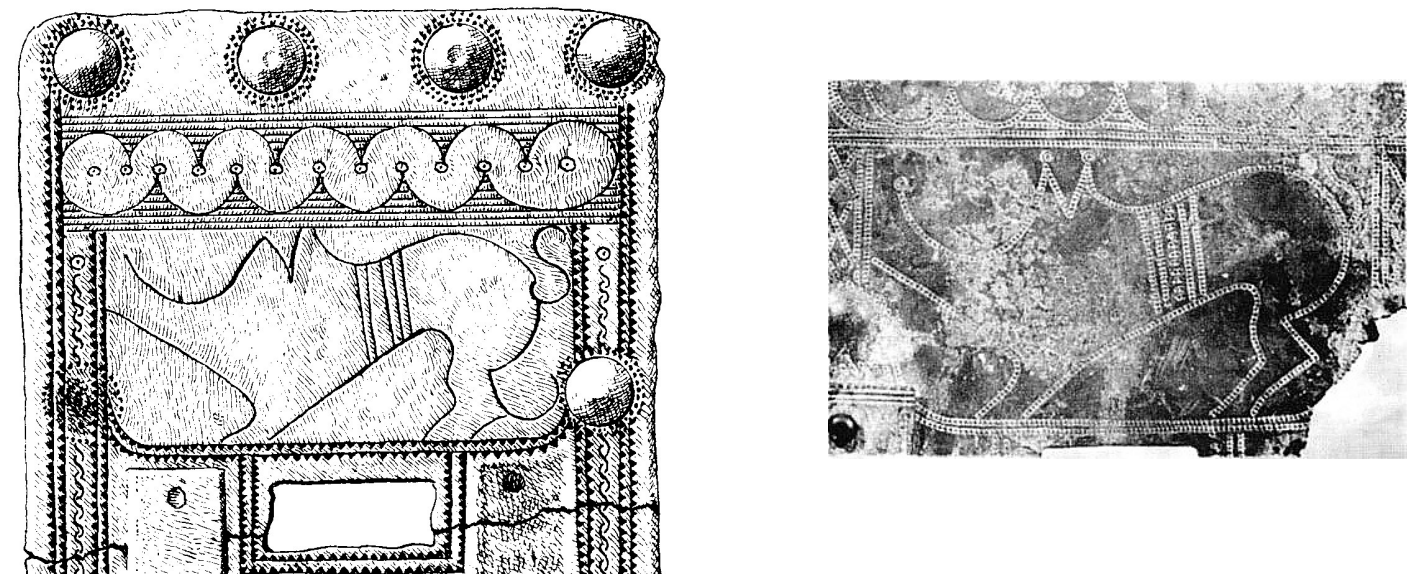

Figura 4C-D, Verraco grabado en broches de cinturón de Miraveche y de Busto de Bureba (A y C, según Schüle, 1969; D, según Rovira y Sanz, 1982).

En relación con la movilidad de las téseras, cabe señalar dos aspectos de interés. Uno es que conocemos tres piezas que, con muy alta probabilidad, hay que considerar salidas del mismo taller, aunque cada una de ellas siguió posteriormente caminos distintos. Una, hasta perderse en la Varea de los bérones, quizás en las luchas sertorianas. Otra ha aparecido en las tierras burgalesas de la celtibérica Vxama Argcela. La tercera, por desgracia, carece de toda procedencia, lo que es muy de lamentar. La conclusión más lógica es pensar que estas téseras se fabricarían casi en serie y se debían llevar consigo para establecer un pacto en el momento oportuno. Al menos en los tres casos señalados, el distinto contenido de la inscripción, el distinto alfabeto utilizado y el ductus de los signos grabados (fig. 3) indican que el pacto de hospitalidad se llevó a cabo por personas distintas y en lugares diferentes, aunque la identidad de los soportes suponga que salieron del mismo taller de producción.

A pesar de desconocerse la procedencia de la mayoría de las téseras, no cabe duda que estos objetos asocian una idea de movilidad, como evidencia el mapa de su dispersión (Almagro-Gorbea y Ballester, 2017, fig. 6), pues tipos de tésera muy diversos y, por lo tanto, de distintos talleres de origen, aparecen repartidos por áreas muy diversas (fig. 5). En este sentido, cabría diferenciar las téseras que documentan contactos dentro de "territorios regionales" o "vecinos", que son las más frecuentes, de algunas que indican desplazamientos a gran distancia. En cualquier caso, eran documentos móviles, probablemente llevados por las elites ecuestres consigo en sus desplazamientos, lo que abunda en su supuesta relación inicial con la ganadería trashumante (Gómez-Pantoja 1995: 505; Salinas de Frías 1999: 292; Sánchez Moreno 2001), aunque más bien su movilidad pudiera reflejar especialmente los grandes movimientos de tropas ocurridos durante la conquista romana, en especial en las guerras sertorianas. En este sentido, las concentraciones de téseras en Extremadura (Almagro-Gorbea y Ballester, 2017, 38 s.), en torno a Contrebia Carbica y Segobriga (Almagro-Gorbea y Lorrio, 2006-7), en el Valle Medio del Ebro (Díaz y Jordán 2006: 257; Olcoz y Medrano 2011: 251; etc.) y en la Cantabria cismontana (Peralta, 1993; id., 2011: 247 s., lám. 3; Jordán, 2014; Torres y Ballester, 2014) apoyan esa hipótesis (fig. 5). Por otra parte, esa dispersión coincide en buena medida con la que ofrecen las fíbulas de jinete y de caballito (Almagro-Gorbea y Torres 1999: mapas 2 y 26) y una dispersión semejante muestran igualmente los puñales de empuñadura biglobular y las fíbulas de tipo La Tène de pie vuelto (id., mapas 28 y 29). Todos estos elementos documentan la expansión de las elites ecuestres celtibéricas hacia áreas periféricas, como el Valle del Ebro, Cantabria y la Extremadura española (Almagro-Gorbea y Lorrio 1986; Almagro-Gorbea y Torres 1999: 109-110), muy probablemente asociada a la expansión de los genitivos de plural en la onomástica (González 1986: mapa final; Almagro-Gorbea y Torres, 1999: mapa 32) y a una paralela celtiberización lingüística 
(Untermann, 1997: 436, mapa 4), probablemente protagonizada por familias celtibéricas gentilicias de rango ecuestre (Almagro-Gorbea y Torres 1999: 109-110 y 115-116).

La idea de movilidad señalada sugiere la existencia de dos posibles "conjuntos cerrados" formados por téseras, que tienen el interés de indicar cómo se debían usar y transportar estas piezas, seguramente llevadas consigo en sus desplazamientos por sus propietarios. Uno se supone que procedería de la zona del Guadarrama entre El Escorial y Segovia (Turiel, 1997); está formado por tres piezas, una tésera tabuliforme en alfabeto celtibérico (CT$1)$, otra tabuliforme en lengua céltica y escritura latina (CT-2) y una tésera anepígrafa en forma de caballo decorada con círculos solares (CT-3), esta última tipológicamente originaria de la Meseta Norte (Almagro-Gorbea y Turiel, 2003: 370). Si se trata de un conjunto cerrado, lo que es muy probable, su ocultación se dataría c. 50-25 a.C. Más seguro parece otro posible conjunto de téseras adquiridas por el
Marqués de Cerralbo a inicios del siglo XX en Sasamón, la antigua Segisamun (TIR, 1993: 207), que hoy se conservan en el Museo Cerralbo (Torija y Baquedano 2007). Lo forman una tésera tauromorfa con escritura celtibérica occidental, otra anepígrafa simétrica en forma de caballo, dos téseras pisciformes, una con escritura romana y lengua céltica y otra anepígrafa, y dos téseras tabuliformes anepígrafas. La aparición a inicios del siglo XX de estas téseras tan similares, datadas c. 75-25 a.C., hacen suponer que proceden de un depósito cerrado, cuya ocultación se puede relacionar muy probablemente con el inicio de las guerras cántabras, cuando los ejércitos romanos y sus auxiliares se concentraron en Segisamun (Floro, Ep. 2,33,48). Este contexto histórico permite atribuir las téseras que forman este depósito de Sasamón a algún individuo que probablemente formaría parte de las tropas auxiliares allí acantonadas el 25 a.C., quien llevaría consigo las téseras en alguna bolsa o contenedor adecuado.

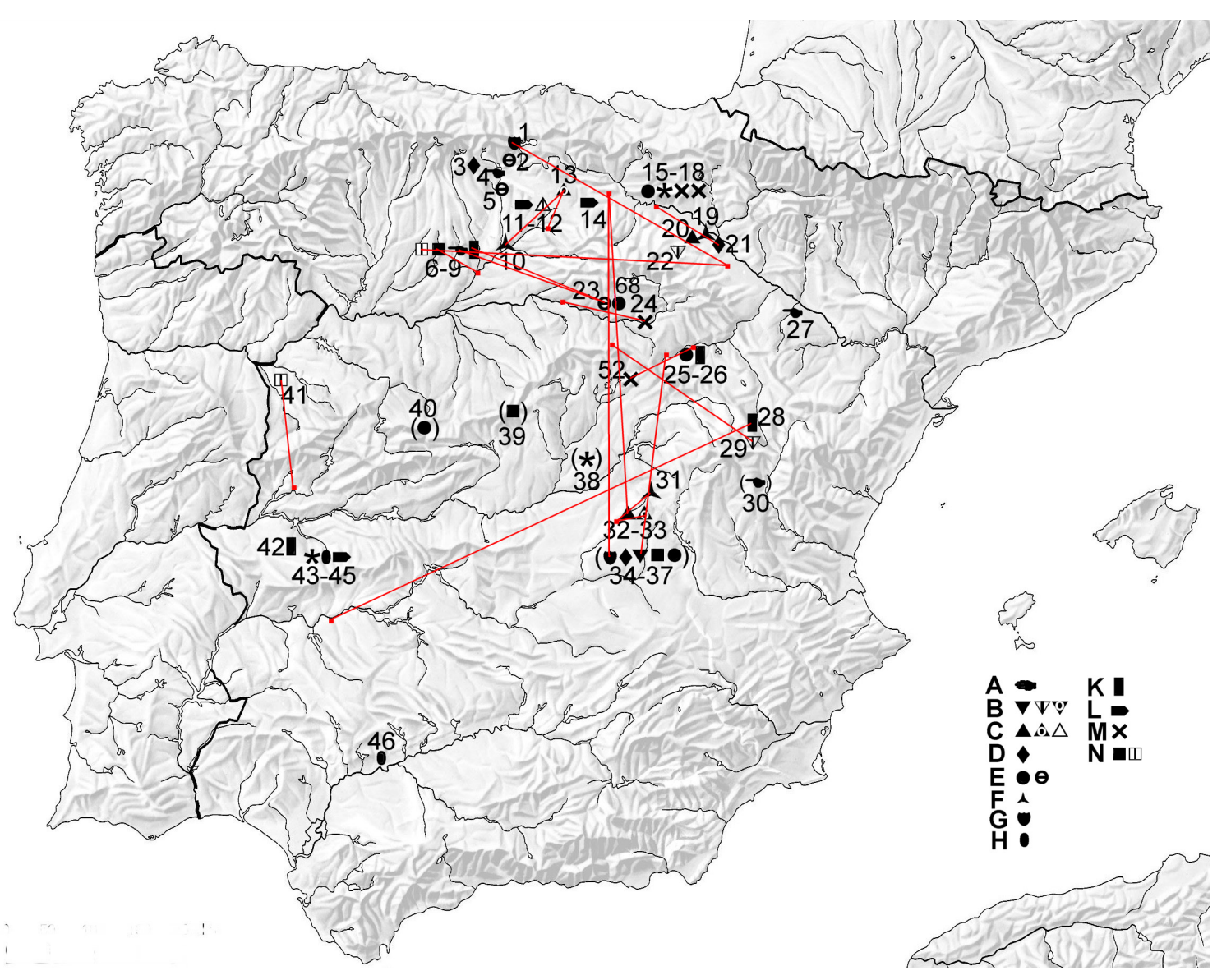

Figura 5. Dispersión y movilidad de las téseras celtibéricas (Almagro-Gorbea y Ballester, 2017). 


\section{Iconografía}

Un último tema de interés de esta nueva tésera de la zona de Osma es el de su iconografía. El jabalí es bien conocido en la mitología indoeuropea como animal maligno y su caza era una empresa heroica (Fornasier, 2001). También está ampliamente documentado en la mitología y en la iconografía céltica, especialmente en los siglos II y I a.C., desde Gran Bretaña hasta Hungría (Green, 1992: 44-45; Kruta, 2000: 807-808), pues se considera que era símbolo del ardor guerrero (Fisher, 1991, 9) y también de la clase sacerdotal druídica (Sergent, 1995, 85).

El jabalí aparece representado en esculturas (Duval, 1977: fig. 200), en monedas (Duval, 1977: fig. 140, 437,A-C, 438,C; Szabó, 1992: 96; Megaw y Megaw, 1994: fig. 246, 299), donde es el animal más frecuente después del caballo (Fisher, 1991, 9, fig. 13 a 18), en figuritas de bronce (Duval, 1977: fig. 169, 367; AA.VV., 1991: 414 y 424; Megaw y Megaw, 1994: fig. 247-24, 371; Szabó, 2001: $67, n^{\circ} 210$ ), generalmente fundidas a la cera perdida (Guillaumet, 1996: 83), y en los conocidos estandartes gálicos (Moreau et al., 1995). Su significado debe asociarse a que era el símbolo de divinidades de la denominada en términos dumezilianos tercera función, responsables de la fecundidad, riqueza y bienestar de la sociedad (Duval, 1976: 52-3 y 93; Blázquez 1977, 227, 284; Green 1992, 44-45), como parece confirmar las pesas de bronce en forma de jabalí (Almagro-Gorbea et al., 2004: $312, \mathrm{n}^{\mathrm{o}}$ 612).

El jabalí también tuvo un significado mítico en Hispania, donde fue ampliamente representado (Almagro-Gorbea y Torres, 1999: 70 s., lám. 29; Abascal, 2002: 25 s), en especial entre celtiberos y pueblos próximos, por ejemplo, en los bien conocidos verracos vettones (Álvarez Sanchís, 1999, 215-216; id., 2003: 60 s.), emplazados en prados seguramente comunales y ante las puertas de oppida (Gutiérrez Robledo, 1999; Martínez Lillo y Murillo, 2003), por ser la representación de numina ctónicos de fecundidad. Igualmente, son bien conocidas las fíbulas en forma de jabalí o de "verraco" características de la Meseta Norte (Cerdeño y Cabanes 1994), quizá relacionadas con ritos iniciáticos (Almagro-Gorbea y Torres 1999: $71 \mathrm{s.}$ ), alguna de las cuales ofrecen incluso la característica moldura en el centro que vemos en este tipo de téseras (vide infra). También aparece un jabalí en la decoración excepcional del citado broche de cinturón de Miraveche (Schüle, 1969: lám. 147, nº 15; Lenetz de Wilde, 1991: n 207, lám. 85c; vide infra), en algún estandarte de esa necrópolis (Schüle, 1969, lám. 151, no 2), en la lúnula del Tesoro de Chaves (Raddatz, 1969: lám. 90 y en pondera (Almagro-Gorbea ed. 2004, $\mathrm{n}^{\circ}$ 606, 612), probablemente por su relación con la divinidad ctónica garante de pactos y pesos.

El contexto iconográfico que ofrece este animal entre los celtas permite considerar que era un animal relacionado con una divinidad infernal de la tercera función (vide supra), que sería la garante del pacto de hospitalidad y que impondría terribles castigos al que quebrantara el pacto. El jabalí es el animal sacrificado en ritos vinculados a juramentos y a pactos en diversas culturas indoeuropeas (Almagro-Gorbea y Torres 1999: 71), cuyo garante era un dios de carácter ctónico (App., Ib. 52: theoùs orkious), quizás el propio Teutates como "Padre del Pueblo" y su Protector y divinidad suprema (Almagro-Gorbea y Lorrio, 2011: 269 s.). Esta tradición indoeuropea explica que el jabalí también formara parte de los ritos ancestrales para sellar un pacto en el derecho fecial romano, que regía las relaciones de paz y guerra de Roma con otros pueblos (Alföldi 1959, 20-21; Martínez-Pinna, 1982, 242 n. 714), en especial en juramentos de federación, como el foedum cequum establecido entre Latino y Eneas (Verg., AEn. 12,166; Serv., ad AEn., 8,641 ), pacto que documenta la iconografía numismática romana (Alföldi 1959, lám. 3,2, 6,1-4 y 6,7-10), en monedas acuñadas en Hispania (García Bellido, 2001).

Este hecho refuerza la hipótesis de que un suido o jabalí fuera el animal sacrificado para sellar el pacto de hospitalidad, pues era el animal sacrificado en diversas culturas indoeuropeas en los ritos vinculados a juramentos y pactos garantizados por divinidades infernales de acuerdo con ritos ancestrales como los conservados en el derecho fecial romano.

En conclusión, esta bella tésera de hospitalidad en forma de suido, por sus características formales, parece proceder del territorio autrigon de la actual Bureba, aunque haya sido hallada en tierras de la ciudad arévaca de Vxama Argcela. Los paralelos estilísticos señalados también permiten apuntar que de- 
bió ser hecha hacia la segunda mitad del siglo II, probablemente hacia finales de ese siglo o a inicios del siglo I a.C., por lo que debe considerarse anterior a las guerras sertorianas, como parece confirmar el ejemplar similar hallado en La Custodia, la antigua Vareia de los bérones, población que se supone que fue destruida en ese conflicto.
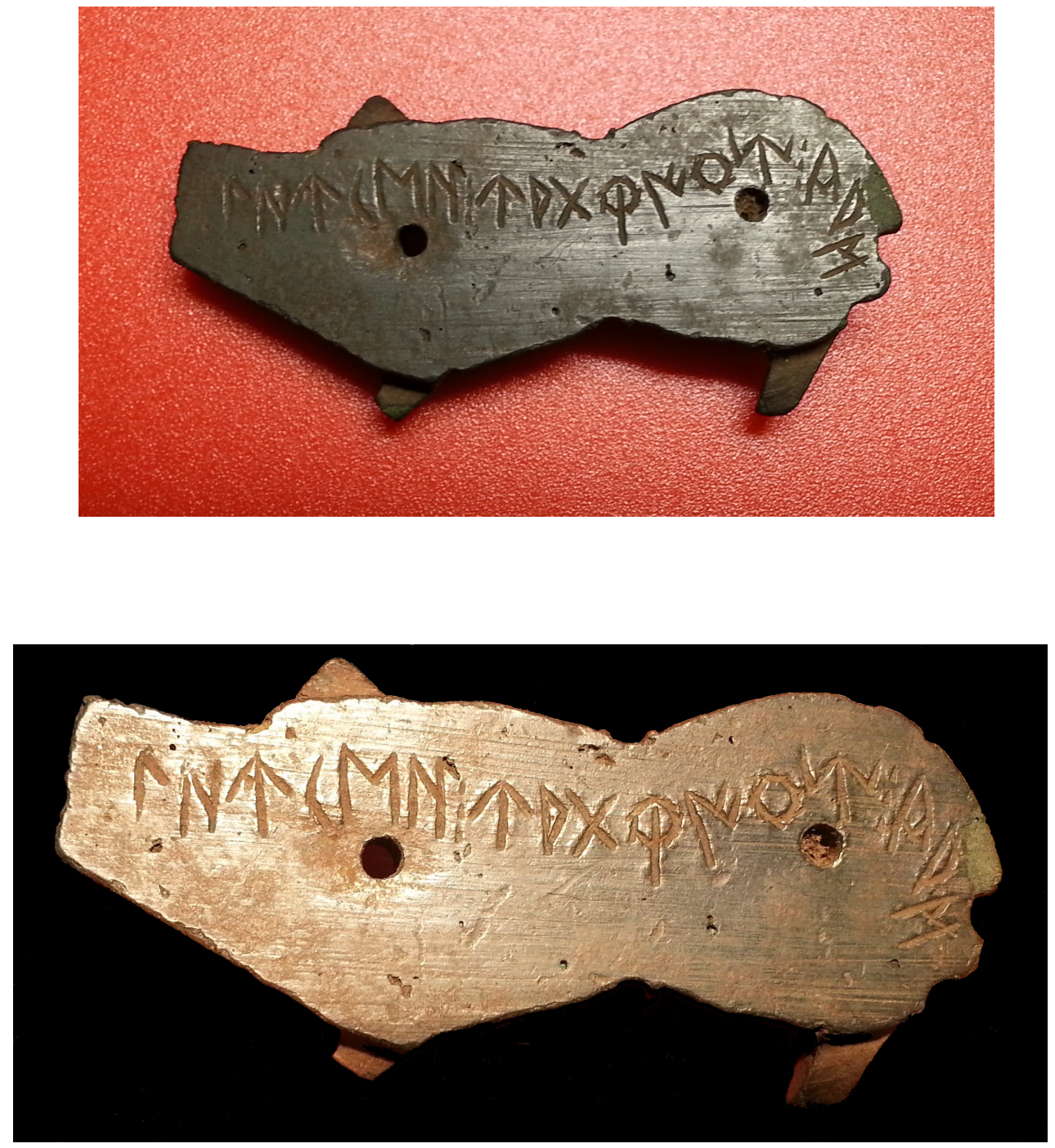

Figura 6A-B, Inscripción del reverso de la tésera de Vxama Argaela.

\section{Estudio lingüístico}

Gracias a la clara ejecución de los signos y a la buena conservación de la pieza, la lectura de la inscripción - aparentemente tres palabras separadas por una interpunción de tres muescas (:) - no ofrece particular dificultad (fig. 6AB):

$$
\uparrow H \uparrow(M H: \uparrow \nabla \times \Phi N \diamond W: A D M
$$

Lo que en transliteración y si, como parece, el texto se atiene al patrón escriturario binoclusivo (uulgo: sistema dual), vendría a ser:

\section{LOUGeSO:UADaRIGUM:CaAs}

Grafemáticamente hay que notar la particularidad de la segunda de las $<_{\mathrm{O}}>$, ambas con barra interior muy inclinada, ya que además 
aquella, a diferencia de la primera, presenta una especie de apéndice o apex contiguo a su extremo superior derecho. No conocemos paralelos para tal signo y es, por tanto, obscura la eventual significación que pudiere tener, aunque sí parece realizado intencionalmente.

Como se anticipó, el texto parece seguir el patrón binoclusivo de diferenciación entre sordas y sonoras ( $<_{\mathrm{Ge}} \mathrm{Da} \mathrm{Gu} \mathrm{Ca}>$ ), aunque al no darse ningún contraste para una misma oclusiva (del tipo, por ejemplo, $<\mathrm{Ce} \mathrm{Ge>}$ ), obviamente no podemos estar seguros de ello.

Contra lo que esperaríamos en razón de la más que posible procedencia geográfica de la pieza, aquí comparece la variante oriental de la nasal labial, práctica más propia de la Celtiberia citerior o zona del valle del Ebro ( $\mathbb{N}^{\vee}$ ).

El texto presenta además registro vocálico redundante ( $\mathrm{CaA})$, es decir: iteración de la vocal inherente al silabemograma, expediente, en cambio, más propio de la ulterior Celtiberia y, de hecho, para tal se dispone de bastantes testimonios en epígrafes procedentes sobre todo precisamente de la zona burgalesa (uide Rubio 2004: 122 o Jordán 2017: 316): Belorado (к.24.1: Seceeios sailetiicoo metaAma), Peñalba de Castro (к.13.1: caAbaARINOS y K.13.2: MUCUUCaAIAU), Sasamón (K.14.1: IROREciIos MONituUCOOS y ALETUURES), además de en la contigua provincia de Soria: Numancia (к.9.2: LUÁNICOO COORINAU y quizá K.9.5: AREBaSICOOO[). Nuestra pieza grafemáticamente coincide además con la de Belorado, que hasta ayer era el «elemento dicordante» (Jordán 2017: 316), por ser la única que, junto a una característica occidental como la redundancia vocálica, presentaba el empleo de las nasales orientales $\left(\mathbb{V}^{\vee} \vDash \times \nabla \mathbb{V}^{\vee} \nabla-\right.$ METaAMA, con $\left\langle\mathbb{V}^{V}\right\rangle$, no con $\langle N\rangle$ ), tal como ocurre también en nuestra pieza $\left(\uparrow \triangleright \times \Phi \vee^{*} \diamond \mathcal{W}^{*}\right)$. Ambas piezas podrían coincidir asimismo en la presentación del patrón binoclusivo, aunque el expediente no pueda darse por seguro para ninguna de las dos.

Sinópticamente, por tanto, podría presentarse así el patrón escriturario seguido en nuestra pieza.

\begin{tabular}{|c|c|c|c|}
\hline grafemas & oclusivas & nasales & vocales \\
\hline patrón & ¿binoclusivo? & oriental & redundante \\
\hline
\end{tabular}

De seguirse el citado patrón binoclusivo, desde el punto de vista fonológico solamente habría que resaltar la sonorización de lo que parece un genitivo plural de las tan comunes formaciones adjetivales celtibéricas en $/ \mathrm{k} /$ : -IGUM. Obviamente antes de postular un proceso de sonorización $(/ \mathrm{k}>\mathrm{g} /)$, documentado muy probablemente en áreas más orientales o periféricas del ámbito hispanocéltico peninsular, verbigracia en los dos CELTIGVN — con verosímil /g/ por /k/, de una epígrafe procedente de Monte Cildá (Palencia; C.I.L. 2,6298) - hay que pensar en una posible incuria gráfica, con omisión del punto central en el signo para no$\operatorname{tar} / \mathrm{ku} /$, o simplemente que no se ha seguido estrictamente el patrón binoclusivo, ya que de modo general en estos casos las escrituras antiguas no son sistemáticas - lo que conviene nunca olvidar - y muchas veces suelen limitar el uso de los diacríticos sólo a aquellas formas para las que hay posibilidad de ambigüedad. Ya, por ejemplo, para la escritura latina los gramáticos recomendaban el empleo del apex -o tilde para marcar las vocales largas - sobre todo para distinguir formas que de otra manera podrían confundirse ( $c f r$. Quintiliano
1,7,2-3; Terencio Escauro 7,33 Keil; Isidoro or. $1,27,29 \ldots)$.

Morfológicamente ya hemos notado lo que parece una desinencia segura de genitivo plu$\mathrm{ral}$. A esta precedería una forma en $-\mathrm{O}$, previsiblemente un genitivo singular temático de una voz de género masculino. La palabra final en -AS sería presumiblemente un acusativo plural - normalmente femenino- de los temas en $-a$, lo que sintácticamente ofrece muchas dificultades. Algunos estudiosos (notoriamente Jordán 2004: 81 y 102) proponen -AS como genitivo singular de los temas en $-a$, aunque esta función parece ser representada más bien por la desinencia celtibérica de [antiguo] ablativo -Az. En todo caso, un tercer genitivo aquí sería igualmente muy difícil de explicar sintácticamente y lo que esperaríamos es un nominativo de acuerdo al típico orden sintáctico propio de las antiguas lenguas indoeuropeas, según el cual los determinantes preceden a los determinados, ordo bien documentado además en muchos otros textos celtibéricos: genitivo singular - genitivo plural - nominativo singular.

Léxicamente las formas carecen de paralelos exactos, si bien para la primera (LOU- 
GeSO) puede al menos invocarse la existencia de una probablemente misma raíz en unos antropónimos procedentes de una inscripción de Pozalmuro (Soria, del s. I d.C.; C.I.L. 2,5797; Abascal y Gimeno 2000: 232 n423a: LOVGESTERI) y otro de Peñalba de Castro (Burgos; véase Hispania Epigraphica 2 [1996] 51-2, $\mathrm{n}^{\circ} 141:$ LOVGESTERICO[N]). También la denominada tésera de El Otero presenta un inicial LOUGeSTeRO (Peralta 2014: 248: LOUKEŚ o LOUGEŚ TERO y 2018: 104-5: LOUGESTERO; Jordán 2014: 718: loukestero). Para el caso de LOVGESTERICO [, cumple recordar que es bien conocida la existencia de un morfema /-ik-/ en las lenguas célticas peninsulares por resultar este en ellas el más frecuente formante adjetival. Por otra parte, -ter- podría remitir a otro formante adjetival indoeuropeo bien conocido y documentado en un buen número de grupos lingüísticos, aunque su origen y antiguos valor o significado son todavía obscuros (véase, por ejemplo, Szemerényi 1987: 253-258). Baste aquí al respecto apuntar su presencia en formas tan conocidas como las latinas magister 'maestro' o minister 'ministro - administrador', formadas respectivamente sobre las mismas bases que magis 'más' y minus 'menos' o como dexter 'diestro - derecho' (cfr. griego dexiterós con igual significado y mismo formante) y sinister 'izquierdo'. De tal morfema hay también testimonio en las lenguas célticas, verbigracia en el denominado ecuativo del irlandés, categoría morfológica exclusiva de las lenguas célticas y empleada junto al comparativo y superlativo para indicar igualdad del tipo 'tan [...] como' (véase McCone 2005: 136-142 y sobre el morfema en la onomástica hispánica y en el ecuativo irlandés Luján 2000: 80-84). De modo que una segmentación como LOVGES-TER[-IC-] dejaría precisamente la exacta base que encontramos en LOUGeS-O. Este texto confirmaría la duda de Jordán sobre la posibilidad de segmentar en LOVGESTERI o LOVGESTERICO [ una secuencia -is-ter-, es decir, con una adicional morfem -is- de carácter indoeuropeo: «la única duda que se nos presenta es por qué la $-i-$ de $-i s-$ se transforma en -es-» (2014: 719). La base léxica sería, pues, propiamente LOUGeS- y no LOUGmás un sufijo *-is. En todo caso, la voz debe de recubrir un andrónimo o nombre de varón, relacionado quizá de algún modo con el dios Lug (Holder, 1904, 306 s.).
Para el segundo vocablo hay que partir de una raíz o, mejor, base léxica *uadar- o *uatar-, base quizá solo casualmente coincidente con la postulada raíz indoeuropea para 'agua [potable]', pero base, en todo caso, para la que, al menos hasta el momento, no contamos con paralelo alguno en el material hispanocéltico conocido, aunque sí alguno más remoto como un VADARIVS en una inscripción de Celtinis (o Castellum Celtianum) en Numidia, pero del s. II d.C. Como fuere, tanto la posición sintáctica como la morfología del vocablo y lo que sabemos de la antroponimia celtibérica apuntan a un nombre propio familiar o de clan.

Como se sugirió, la más problemática es la tercera de las formas, ya que morfológicamente -AS debería corresponder a un acusativo plural o eventualmente a un genitivo singular, pero uno y otro caso darían por resultado una secuencia sintáctica muy anómala dentro de una frase o sintagma puramente nominal. Para tal forma no disponemos de paralelos fuera del muy probable $\mathrm{CaS}$ de la tésera de Otero (Peralta 2014: BOKAŚ y 2016: 104-7: KAŚ; Jordán 2014: 720: lanian/kạs) y el CaA SA de la tésera de Monte Bernorio (Torres y Ballester 2014: 268), formas ambas que aparecen también en posición final. La secuencia CaA SA - claramente separado por una interpunción- de Monte Bernorio sigue además a una forma en -UM, más concretamente ]-IUM, igual que en la tésera que aquí comentamos. Queda, no obstante, otra opción: considerar la posibilidad de que estemos ante alguna[s] abreviatura[s]. Como es sabido, en muchas téseras idénticas o muy similares en su estructura inicial nos encontramos al final con la ubicua forma $\mathrm{CaR}$ —verosímilmente / ka:r/ - la cual, como se acepta de modo ya casi unánime, vendría a equivaler en significado al sintagma tessera hospitalis que encontramos en este mismo tipo de piezas cuando vienen redactadas en latín. La inicial con la oclusiva aparentemente sorda apunta en esta misma dirección. Así las cosas, quizá podría segmentarse aquí $\mathrm{CaA}-\mathrm{S}$, viendo en $\mathrm{CaA}$ - una abreviación de $\mathrm{CaA}[\mathrm{R}]$ y en -S a su vez la abreviatura habitualmente interpretada como nominativo femenino singular de un demostrativo, es decir: -S[A] (véase Wodtko 2000: 311 o Jordán 2004: 156), en la línea, por tanto, de la hipótesis planteada para la secuencia CaA SA de Monte Bernorio (Torres y Ballester 2014: 274-5). Todo ello resulta evidentemente muy especulativo, si bien, por tratarse de una fórmula ritual y repetitiva, la 
ubicua forma $\mathrm{CaR}$ - o aquí CaAR con patrón vocálico redundante - sería en sede teorética una buena candidata para una experimentar una abreviación gráfica.

En lo concerniente a la semántica del texto, gracias a su parcialmente clara estructura morfosintáctica podemos proponer una traducción aproximada e incompleta del tipo: "[¿tésera X?] de Lugeso de los vadárigos".

Habrá que estar atentos en el futuro a la eventual y siempre deseable emergencia de textos paralelos y que puedan precisar, sobre todo en su más opaco tramo final, el texto de esta nueva tésera procedente de la vieja Úxama.

\section{Referencias}

AA.VV., 1991: I Celti, Milano.

Abascal, J. M., 2002: "Téseras y monedas, iconografía zoomorfa y formas jurídicas de la celtiberia", $\mathrm{Pa}$ laeohispanica, 2, 19-25.

—y Gimeno, H., 2000: Epigrafia Hispánica, Real Academia de la Historia, Madrid.

Abásolo, J. A. y Ruiz Vélez, I., 1978: "La necrópolis de Miranda de Ebro. Materiales para su estudio", Estudios de Arqueología Alavesa, 9, 265-272.

Alföldi, A., 1959: "Hasta - Summa Imperii. The Spear as Embodiment of Sovereignty in Rome", American Journal of Archaeology 63,1, 1-59.

Almagro-Gorbea, M., 2003: Real Academia de la Historia. Catálogo del Gabinete de Antigüedades, Epigrafia Prerromana, Madrid.

Almagro-Gorbea, M. y Ballester, X., 2017: "Dos Nuevas Téseras de Hospitalidad Hispanocélticas en Latín. Una Aportación al Estudio de las Téseras Hispanocélticas", Lyburna, 10, 19-45.

Almagro-Gorbea, M., Casado, D., Fontes, F., Mederos, A. y Torres, M., 2004: Real Academia de la Historia. Catálogo del Gabinete de Antigüedades. Antigüedades Españolas I. Prehistoria, Madrid.

Almagro-Gorbea, M. y Lorrio A. J., 1986: "La expansión céltica en la Península Ibérica: una aproximación cartográfica”, I Simposium sobre los celtiberos, Zaragoza 1986, 105-122.

—, 2006-2007: "De Sego a Augusto: los orígenes celtibéricos de Segobriga", Boletín del Seminario de Arte y Arqueología de Valladolid. Arqueología 72-73, 143-181.

—, 2011: Teutates. El Héroe Fundador y el culto heroico al antepasado en Hispania y en la Keltiké (Bibliotheca Archaeologica Hispana 36), Madrid.

Almagro-Gorbea, M. y Torres, M., 1999: Las fibulas de jinete y de caballito. Aproximación a las elites ecuestres y su expansión en la Hispania céltica, Zaragoza.

Almagro-Gorbea, M. y Turiel, M., 2003: “Colección Turiel”, en M. Almagro-Gorbea, Real Academia de la Historia. Catálogo del Gabinete de Antigüedades. Epigrafia Prerromana, Madrid, 369-379.

Álvarez-Ossorio, J., 1941: Museo Arqueológico Nacional. Catálogo de los exvotos de bronce, ibéricos, Madrid.

Álvarez Sanchís, J., 1999: Los Vettones (Bibliotheca Archaeologica Hispana, 1), Madrid.

—, 2003: Los señores del ganado. Arqueología de los pueblos prerromanos en el Occidnete de Iberia, Madrid.

Argente, J. L., 1989: Las fibulas de la Edad del Hierro en la Meseta Oriental. Su valoración tipológica, cultural y cronológica (Excavaciones Arqueológicas en España 168), Madrid.

Blázquez, J. M., 1977: Imagen y mito. Estudio sobre religiones mediterráneas e ibéricas, Madrid.

Cabré, J., 1937: "Broches de cinturón, de bronce, damasquinados de oro y plata", Archivo Español de Arte y Arqueología, 38, 93-126.

Cabré de Morán, E. y Cabré, J. A., 1979: "Ensayo tipológico de las fíbulas con esquema de La Tène en la Meseta Hispánica”, Boletín de la Asociación Española de Amigos de la Arqueología, 11-12, 10-26.

—, 1982: "Ensayo cronológico de las fíbulas con esquema de la Tène en la Meseta Hispánica", Asociación Española de Amigos de la Arqueología, 15, 4-27.

Caprile, P., 1986: Estudio de los objetos de adorno del Bronce Final y Edad del Hierro en la provincia de Álava (Estudios de Arqueología Alavesa, 14), Vitoria.

Castellano, A. y Gimeno, H., 1999: "Tres documentos de hospitium inéditos", en F. Villar y F. Beltrán, eds., Pueblos, lenguas y escrituras en la Hispania prerromana. Actas del VII Coloquio de Lenguas y Culturas Paleohispánicas. Zaragoza-1997, Salamanca, 359-374. 
Cerdeño, M ${ }^{a}$ L. y Cabanes, E. 1994: “El simbolismo del jabalí en el ámbito céltico peninsular”, Trabajos de Prehistoria, 2, 51,2, 103-119.

Chaves, F., 1996: Los Tesoros en el sur de Hispania. Conjuntos de Denarios y Objetos de Plata Durante los Siglos II y I a.C., Sevilla.

Díaz, B. y Jordán, C. 2006: “Dos nuevas téseras de hospitalidad procedentes de Fitero (Navarra)”, Palaeohispanica 6, 257-266.

Duval, P.-M., 1976: Les dieux de la Gaule², Paris.

_, 1977: Les Celtes (L'univers des formes), Paris.

Faria, A. Marques de, 1998: "Duas novas tésseras celtibéricas de procedência desconhecida", Revista Portuguesa de Arqueologia, 1,2, 119-121.

Fisher, B., 1991: “Le bestiaire des monnaies gauloises", Cahiers numismatiques, 28, n 110, 7-15.

Fornasier, J., 2001: Jagddarstellungen des 6.-4. Jhr. V. Chr. Eine ikonographische und ikonologische Analyse, Ugarit Verlag, Münster.

García Bellido, A., 1996: "Tessera hospitalis del año 14 de la era hallada en Herrera del Pisuerga", Boletín de la Real Academia de la Historia, 159, 149-166.

García Bellido, M. P., 2001: "Roma y los sistemas monetarios provinciales. Monedas romanas acuñadas en Hispania en la Segunda Guerra púnica”, Zephyrus, 53-54, 551-557.

Gómez-Pantoja J., "Pastores y trashumantes de Hispania", en F. Burillo coord., Poblamiento celtibérico. III Simposio sobre los celtíberos, Zaragoza 1995, 495-505.

González, M ${ }^{a}$ C., 1986: Las unidades organizativas indígenas del área indoeuropea de Hispania, Universidad del País Vasco, Vitoria.

Green, M. J., 1992: Dictionary of Celtic Myth and Legend, London.

Guillaumet, J.-P., 1996: L'artisanat chez les Gaulois, Paris.

Gutiérrez Robledo, J. L., 1999: "Un verraco en las murallas”, Descubrir el Arte, 8, 112-113.

Holder, A., 1904: Alt-celtischer Sprachschatz, II, Leipzig.

Jimeno, A., de la Torre, J. I., Berzosa, R. y Martínez, J. P. 2004: La Necrópolis Celtibérica de Numancia (Arqueología en Castilla y León 12), Valladolid.

Jordán, C., 2004: Celtibérico, Universidad de Zaragoza, Zaragoza

—, 2014: “Una tésera celtibérica de Cantoral de la Peña (Palencia)”, Á. Martínez et alii, coord., Ágalma. Ofrenda desde la Filología clásica a Manuel García Teijeiro, Valladolid, 715-721.

—, 2017: "Sistema dual y redundante en celtibérico", Palaeohispanica 17, 315-327.

Kruta, V., 2000: Les Celtes. Histoire et dictionaire, Paris.

Labeaga, J. C., 1987: “Amuletos mágicos y téseras de hospitalidad en los yacimientos arqueológicos de Viana", Primer Congreso General de Historia de Navarra (Pamplona, 1986) (Príncipe de Viana, Anexo 7), Pamplona, 453-463.

—, 1989: "Algunas fíbulas zoomorfas del poblado La Custodia, Viana (Navarra)", XIX Congreso Nacional de Arqueología (Castellón de la Plana, 1987), Zaragoza: 645-657.

_ , 1991-1992: "Los broches de cinturón en el poblado de La Custodia, Viana (Navarra)", Trabajos de Arqueología Navarra, 10, 317-336.

—, 2006: "Fíbulas de La Tène en el poblado de La Custodia", Cuadernos de Arqueología de Navarra, 14, 177-198.

Labeaga, J. C. y Untermann, J., 1994: “Las téseras del poblado prerromano de La Custodia, Viana (Navarra). Descripción, epigrafía y lingüística", Trabajos de Arqueología Navarra, 11, 54-93.

Lenerz-de Wilde, M., 1987: "Problemas de la datación de fíbulas en la Meseta Hispánica", Zephyrus 3940, 199-213.

- 1991: Iberia Celtica. Stuttgart.

Lorrio, A. J., 1997 (reed. 2005): Los Celtíberos, Madrid.

Lorrio, A. J. y Sánchez de Prado, M D., 2009: La necrópolis celtibérica de Arcóbriga (Monreal de Ariza, Zaragoza), Zaragoza.

Lorrio, A. J., 2007: “Una fíbula del Museo Arqueológico Municipal de Lorca y las fíbulas lobunas celtibéricas", Alberca 5, 2007, 53-66.

Luján E., 2000: "Sobre los orígenes de los comparativos indoeuropeos en *-teros", Revista Española de Lingüística, 30.1, 77-102.

Martínez Lillo, J. L. y Murillo, J. I., 2003: "Últimas actuaciones arqueológicas en las murallas”, en A. Barrios, ed., La Muralla de Ávila, Madrid, 268-291. 
Martínez Pinna, J., 1982: "Reflexiones en torno al foedus Cassianum", Italica 16, 1982, 45-58.

McCone, K., 2005: L'irlandese antico e la sua preistoria, trad. E. Roma, Edizioni dell'Orso, Alessandria.

Megaw, R. y Megaw, V., 1994: Celtic Art. From its beginnings to the Book of Kells ${ }^{2}$, London.

Moreau, J., Ankner, D., Boudet, R., Dhénin, M. y Fecht, M., 1995: Le Sanglier-enseigne gaulois de Soulacsur-Mer (Gironde). Étude de l'emblématique du sanglier dans le monde celtique, Soulac-sur-Mer.

Moure, A. y Ortega, L., 1981: "Fíbulas con esquema de La Tène procedentes de Paredes de Nava", Numantia, 1, 133-146.

Olcoz, S. y Medrano, M., 2011: "Una tésera de hospitalidad procedente de Cascante (Navarra)", Veleia 28, 245-251.

Peralta, E., 1993: "La tésera cántabra de Monte Cildá (Olleros de Pisuerga, Palencia)", Complutum, 4, 223-226.

—, 2011: "Los Cántabros de los orígenes a la conquista romana”, Actas do III Congresso Internacional sobre Cultura Celta, Nalón-2011, 243-292.

—, 2014: «Los Cántabros: de los orígenes a la conquista romana”, Os Celtas da Europa Atlántica. Actas do III Congreso Internacional sobre cultura celta, 15, 16 y 17 de abril 2011 Narón, Instituto Galego de Estudos Célticos, Lugo, 243-292.

—, 2018: "La Tésera de Hospitalidad Prerromana de El Otero y los Cántabros Camaricos”, Liburna, 13, 93-143.

Raddatz, K., 1969: Die Schatzfunde der Iberischen Halbinsel (Madrider Forschungen 5). Berlin, 1969.

Rovira, S. y Sanz Nájera, Ma , 1982: “Análisis tecnológico de varias piezas metálicas procedentes de Busto de Bureba (Burgos)", Boletín de la Asociación Española de Amigos de la Arqueología, 16, p. 44-51.

Rubio Orecilla, F. J., 2004: "La tésera celtibérica de Sasamón (K.14.1)”, Emerita 72.1, 121-153.

Salinas de Frías, M., 1999: "En torno a viejas cuestiones: guerra, trashumancia y hospitalidad en la Hispania prerromana", en F. Villar y F. Beltrán, eds., Pueblos, Lenguas y Escrituras en la Hispania Prerromana. Actas del VII Coloquio sobre lenguas y culturas paleohispánicas, Salamanca, 281-293.

Sánchez Moreno, E. 2001: "Cross-cultural Links in Ancient Iberia: Socio-economic Anatomy of Hospitality", Oxford Journal of Archaeology 20,4, 391-414.

Schüle, W., 1969: Die Meseta-Kulturen der Iberischen Halbinsel (Madrider Forschungen 3). Berlin.

Sergent, B., 1995: Lug et Apollon, Bruxelles.

Simón, I., 2008: “Cartografía de la epigrafía paleohispánica I. Las téseras de hospitalidad”, Palaeohispanica 8, 127-142.

—, 2013: Los soportes de la epigrafía paleohispánica. Inscripciones sobre piedra, bronce y cerámica, Zaragoza.

Szabó, M., 1992: Les Celtes de l'Est. Le Second Age du Fer dans la cuvette des Karpates, Paris.

—, 2001: Les Celtes en Hongrie, Lyon.

Szemerényi, O., 1987: Introducción a la Lingüística Comparativa ${ }^{2}$, trad. A. Álvarez, Gredos, Madrid.

TIR, 1993: Tabula Imperii Romani. Hoja K-30: Madrid. Caesaravgvsta. Clvinia, Madrid.

Torija, A. y Baquedano, I., 2007: "Las tesserae de la Colección Cerralbo. Viejas conocidas, nuevas perspectivas", Paleaohistoria, 7, 269-336.

Torres J. y Ballester, X., 2014: "La tésera de hospitalidad del oppidum de Monte Bernorio (Villalén de Valdavia, Palencia)", Paleohispanica 14, 263-286.

Tovar, A., 1983: “Una nueva pequeña tésera celtibérica”, Emerita, 51, 1-3.

_, 1989: Iberische Landeskunde, II,3. Las tribus y las ciudades de la antigua Hispania, 3, Tarraconensis, Baden-Baden.

Turiel, M., 1997: Tésera Turiel, celtibérica, bialfabética, completa, Madrid, 1997.

Untermann, J., 1997: Monumenta Linguarum Hispanicarum. Band IV. Die tartessischen, keltiberischen und lusitanischen Inschriften, Dr. Ludwig Reichert Verlag, Wiesbaden.

Wodtko, D. S., 2000: Monumenta linguarum Hispanicarum. Band v.1. Wörterbuch der keltiberischen Inschriften, Dr. Ludwig Reichert Verlag, Wiesbaden. 